\title{
Ku and the Stability of the Genome
}

\author{
Anna A. Friedl* \\ Strahlenbiologisches Institut der Universität München, Schiller Straße 42, 80336 München, Germany
}

Received 1 November 2001; revised 26 November 2001; accepted 11 December 2001

\begin{abstract}
$\mathrm{Ku}$ proteins are associated with a variety of cellular processes such as repair of DNA-double-strand breaks, telomere maintenance and retrotransposition. In recent years, we have learned a lot about their cellular and molecular functions and it has turned out that $\mathrm{Ku}$-dependent processes affect the stability of the genome, both positively and negatively, in several ways. This article gives an overview on the role of $\mathrm{Ku}$ in determining the shape of the genome.
\end{abstract}

\section{INTRODUCTION}

$\mathrm{Ku}$ proteins are heterodimers consisting of subunits with sizes of about $70 \mathrm{kd}$ and about $80 \mathrm{kd}$, respectively, that are conserved in a variety of eukaryotes [1]. The heterodimer binds with high affinity to double-stranded DNA ends and hairpin structures. In mammalian cells, Ku bound to DNA ends activates the catalytic subunit of the DNA-dependent protein kinase (DNA-PK) and phenotypes of Ku-deficient cells largely overlap with phenotypes of cells deficient in this catalytic subunit. The yeasts Saccharomyces cerevisiae and Schizosaccharomyces pombe lack the catalytic subunit of DNA-PK. Nevertheless, the functions of $\mathrm{Ku}$ seem to be very similar in these lower eukaryotes and in mammalian cells. Involvement of $\mathrm{Ku}$ in the repair of DNA double-strand breaks (DSB) was not only demonstrated in yeast and mammalian cells, but also in Drosophila melanogaster, Xenopus laevis, and chicken $[2,3,4]$. Ku participates also in $\mathrm{V}(\mathrm{D}) \mathrm{J}$ recombination and immunoglobulin gene class switch $[5,6,7]$, where joining between distant genomic regions is initiated by site- or region-specific DSB, respectively. At least in yeast and mammalian cells, $\mathrm{Ku}$ has an additional function in telomere maintenance, whose absence causes genomic rearrangements, and in processes associated with retrotransposition.

\section{KU AND THE FIDELITY OF DSB REPAIR}

All known pathways for the elimination of DSB can lead to genetic alterations. Homologous recombination can result in sequence alterations due to gene conversion mechanisms if the donor and the receptor molecule differ within the repair patch region (see [8] for a review of homologous recombination).

When associated with a cross-over, interchromosomal homologous recombination can also lead to a recombination of markers flanking the repair patch. In the case of ectopic homologous recombination, this may cause reciprocal translocations. Intrachromosomal homologous recombina- tion may result in deletion events. When taking place between sister chromatids, DSB repair by homologous recombination bears a very low risk of introducing genetic alterations, and there are indications that sister chromatids are preferred to homologous chromosomes or ectopic regions of sequence homology, as donor of information $[9,10]$. In contrast, end-joining mechanisms have a high potential for introducing genetic alterations during DSB repair. Whether or not end joining can restitute the original sequence, is to a large extent influenced by the conformation of the ends to be joined.

End-joining mechanisms and the function of the $\mathrm{Ku}$ proteins in end joining have been extensively reviewed (eg, $[1,11,12])$ and only an overview of the available information is given here. End joining was investigated on a molecular level in yeast, Xenopus, and a variety of mammalian cell lines. Mostly, plasmid rejoining assays were used where plasmids were linearized by restriction digest and then transformed/transfected into cells or incubated with cell extracts, followed by a determination of the relative frequency of joining and sequence analysis of the junction sites (eg, $[13,14,15,16,17,18])$. In other investigations, chromosomal DSB were induced by site-specific endonucleases (eg, $[14,19,20])$. While there are organism-specific differences with regard to the joining efficiency of various end conformations (such as complementary or noncomplementary single strand protrusions and blunt ends) and the degree of dependence of these joining reactions on $\mathrm{Ku}$, the following general picture emerges: provided that the conformation of ends allows for restitution of the original sequence (eg, in the case of complementary overhangs), Ku-dependent end joining is a rather accurate process in mammalian cells and $S$ cerevisiae $[13,16,17]$ (but not in $S$ pombe [18]). In the absence of functional $\mathrm{Ku}$ proteins, alternative end-joining mechanisms are used that appear to largely depend on base pairing between regions of microhomology (ie, one to several bases of homology) exposed by single strand resection or unwinding of the double strand. Microhomology-dependent joining is 
associated with the generation of deletions at the break sites and it has been proposed that $\mathrm{Ku}$ is required for protection of ends against nucleolytic attack. The deletion sizes may, however, also reflect positions of microhomology that allow stable strand-annealing.

When DSB are induced by radical attack (eg, after ionizing irradiation), the ends do not necessarily terminate in complementary single-strand protrusions. To mimic this situation, in some studies, noncomplementary ends were produced by digestion with combinations of restriction enzymes. Joining of noncomplementary ends is intrinsically an inaccurate process that will lead to sequence alterations, but again $\mathrm{Ku}$-independent joining of these ends relies more on microhomology-mediated base pairing associated with deletion formation than does $\mathrm{Ku}$-dependent joining [16, 17]. Current models propose that $\mathrm{Ku}$ serves as an alignment factor that facilitates joining reactions in the absence of sufficiently stable base-pair interactions between the ends to be joined, thus minimizing the need for end processing and, therefore, the nucleotide loss at the junction site [17]. Recently, it was also shown that the $\mathrm{Ku}$-dependent process in vitro mediates accurate joining of complex DSB with partially cohesive overhangs terminating in $3^{\prime}$-phosphoglycolate, a substrate expected to occur upon radical-induced DNA breakage [21].

While $\mathrm{Ku}$-independent end joining was observed in all organisms studied so far, its efficiency seems to vary between organisms. In yeast, inactivation of $\mathrm{Ku}$ drastically reduces the end-joining frequency, suggesting that Ku-independent mechanisms are rather inefficient. In contrast, in mammalian cells, the absence of functional Ku has little effect on plasmid joining frequencies, suggesting that Ku-independent mechanisms can take over efficiently for this kind of substrate $[15,16]$.

When judging the fidelity of end joining, we have also to consider the probability of mis-rejoining, that is, the joining of ends originating from different breaks. Mis-rejoining involves insertions of DNA fragments at break sites as well as interactions between chromosomal breaks that result in genomic rearrangements. In $S$ cerevisiae, insertion of DNA fragments lacking homology to the genomic DNA is a very inefficient process, the efficiency of which can be increased by treating the cells with DSB-inducing agents such as ionizing radiation. This increase is not seen in $\mathrm{Ku}-$ deficient mutants, thus demonstrating a major role for the $\mathrm{Ku}$-dependent end-joining mechanism in insertions occurring at break sites [22]. While nonhomologous integration in mammalian cells occurs readily, $\mathrm{Ku}$-dependence of this process has also been shown by some authors (eg, [23]), but not by others (eg, [19]). Since the genetic requirements for $\mathrm{Ku}$-independent end joining are not yet clear, its influence on repair-associated insertions remains to be elucidated. Extrachromosomal DNA fragments that may be inserted into chromosomal DNA in the course of DSB repair include pieces of organelle DNA and cDNAs [24], and possibly excised chromosomal fragments, or even foreign DNA. Hence, end-joining mechanisms may be involved in phenomena such as mitochondrion-to-nucleus transfer of genetic information, sequence duplications or horizontal gene transfer.

Treatment of cells with ionizing radiation or other strand-break inducing agents leads to chromosome rearrangements due to mis-repair of DSB. As mentioned before, they may result from cross-overs during homologous recombination between inappropriate sites or from mis-rejoining of chromosomal ends. Because of the redundancy of DSB repair mechanisms, the relative contribution of individual mechanisms to the generation of chromosomal rearrangements is difficult to analyze. In $S$ cerevisiae mutant strains unable to perform DSB repair via homologous recombination, radiation-induced chromosomal aberrations (mainly exchange-type aberrations) occur with high frequency and their occurrence depends on functional $\mathrm{Ku}$ [25]. Similarly, radiation-induced exchange-type aberrations are considerably increased in the DT40 chicken B-lymphocyte cell line when homologous recombination is impaired by inactivation of RAD54, but not when KU70-dependent end joining is inactivated [4]. These data suggest a major role for the $\mathrm{Ku}$-dependent repair process in the generation of repairassociated exchanges. In mammalian cells, however, the absence of functional $\mathrm{Ku}$ results in increased frequencies of spontaneous exchange-type aberrations, and inactivation of DNA ligase IV, which participates in $\mathrm{Ku}$-dependent end joining, enhances the frequency of radiation-induced exchanges [26]. A possible explanation for these differences may lie in species-dependent variations in the efficiency of $\mathrm{Ku}$-independent end-joining pathways that may also readily mis-rejoin chromosomal ends. Since mis-rejoining requires physical vicinity of ends resulting from different breaks, the number of breaks present at a given time in a cell nucleus may also affect the formation of exchanges. This number is affected not only by the dose of irradiation, but also by the kinetics of (correct) DSB elimination, thus complicating comparisons between different experimental systems. Nevertheless, a recent study, based on the restitution of fulllength chromosomal restriction fragments after irradiation, demonstrated a dependence of mis-rejoining on the $\mathrm{Ku}$ mediated process also in mammalian cells [27].

\section{KU AND THE STABILITY OF CHROMOSOME ENDS}

Telomeres are specific nucleo-protein structures at the ends of linear chromosomes (see [28] for a recent review). One of their functions is to enable template-independent elongation, thus allowing to overcome the end-replication problem. In most eukaryotes, elongation of the telomeric repeat tract is performed by telomerase. In addition, telomereassociated proteins form a so-called cap that protects the telomeres from degradation and recombination processes. This cap also enables the cell to differentiate between natural chromosome ends and unnatural ends caused by DSB, thereby inhibiting end-to-end fusions between chromosomes. This article concentrates on the influence of telomereassociated $\mathrm{Ku}$ on genome stability and the reader is referred to recent reviews covering additional aspects of $\mathrm{Ku}-$ dependent processes in telomere metabolism $[28,29]$. 
When telomeric repeat DNA is lost in telomerasedeficient mammalian cells, fusions between chromosome ends are observed that lead to dicentric fusion chromosomes [30]. A concomitant loss of the proliferative capacity, the so-called cellular senescence, can at least partially be explained by anaphase bridges and breakage-fusion cycles. Some cells in senescent populations gain the capability of elongating their telomeres by telomerase-independent ALT (alternative lengthening of telomeres) mechanisms that probably depend on recombination between telomeric repeat tracts [31]. Recombination between subtelomeric repetitive sequence elements may also contribute to telomere stabilization in telomerase-deficient cells [32]. Telomerasedeficient yeast cell also undergo cellular senescence when the telomeric repeat tract is eroded; and survivors, which escape senescence, use mechanisms of alternative telomere maintenance that are similar to those observed in mammalian cells. Survivors in $S$ cerevisiae exhibit strong amplification of the subtelomeric so-called $\mathrm{Y}^{\prime}$ elements or strongly elongated telomeric repeat tracts. Different recombinative subpathways appear to be responsible for $\mathrm{Y}^{\prime}$ amplification and telomere elongation in $S$ cerevisiae survivor cells $[28,29]$. In $S$ pombe survivor cells, linear chromosomes, in which subtelomeric repetitive sequences are amplified, were observed. In addition, by end-to-end fusion, circularized chromosomes (rather than chromosome fusions) occur with high frequency [33].

In normal cells, recombination between telomeric or subtelomeric sequences and end-to-end fusions are suppressed. Recent research suggests that suppression depends not directly on the length of the telomeric repeat tract, but on the integrity of the proteinaceous cap. Ku bound to telomeres, either directly (as in S cerevisiae, [34]) or indirectly (as suggested for mammalian cells, [35]), appears to provide capping functions: in Ku-deficient mammalian cells, end-to-end fusions occur independently of the length of the telomeric repeat tract, demonstrating that $\mathrm{Ku}$ prevents such fusions and that these fusions are not produced by $\mathrm{Ku}$-dependent end joining [36, 37, 38]. In Ku-deficient yeast cells, rearrangements and amplification of subtelomeric repetitive elements are observed, suggesting that $\mathrm{Ku}$ is involved in inhibiting recombinative processes in telomereassociated regions $[39,40]$. Recombination is also thought to cause rabid shortening of artificially elongated telomeric tracks in Ku-deficient $S$ cerevisiae [41].

\section{KU AND THE MOBILITY OF RETROELEMENTS}

Several recent studies show that the presence of functional $\mathrm{Ku}$ affects the outcome of retroviral infection in mammalian cells. Initial studies suggested a function for $\mathrm{Ku}$ (and other factors required in $\mathrm{Ku}$-dependent end joining) in the repair of the gapped integration intermediate that results when retroviral integrase joins the 3 '-terminal nucleotide of viral cDNA to staggered phosphates in the host DNA [42]. This view has subsequently been challenged, and it was proposed that $\mathrm{Ku}$-dependent end joining may be required for circularization of unintegrated viral DNA (thus preventing apoptosis induced by the presence of viral DNA ends in host cells), or for repairing DSB induced in host DNA by unspecific endonucleolytic activity of free integrase molecules $[43,44,45]$. In support of the latter model, it has been observed that expression of HIV integrase is lethal in yeast mutants deficient for homologous recombination, the major DSB repair pathway in this organism [46].

The yeast $S$ cerevisiae possesses retrotransposons (Ty elements) that resemble retroviruses and generate intracellular virus-like particles. $\mathrm{Ku}$ has been shown to physically associate with these particles [47] and with retroviral preintegration complexes in mammalian cells [45]. Interestingly, in $S$ cerevisiae, the presence of $\mathrm{Ku}$ affects the substrate specificity of Ty integrase: when Ku-deficient yeast cells are transformed with linear plasmids lacking homology to the yeast genome, about $90 \%$ of the integration reactions depend on the expression of Ty elements, and the integrations show hallmarks of Ty integrase-mediated reactions. In contrast, in $\mathrm{Ku}$-proficient cells, integration of plasmid DNA does not depend on Ty metabolism [22]. Ku, functioning as a cellular factor that determines integrase substrate specificity, may explain why integrase-mediated integration of Non-Ty-DNA was never observed in vivo, while it can readily be demonstrated in vitro [48].

\section{CONCLUSIONS}

The Ku proteins, as well as additional proteins involved in $\mathrm{Ku}$-dependent end joining, are generally regarded as caretakers of genomic stability (eg, [49]) and indeed, increased chromosomal instability is seen when these proteins are inactive in mammalian cells. Ku-dependent end joining is a major DSB repair mechanism in mammalian cells, in the absence of which many breaks either remain unrepaired or are processed by other mechanisms that may cause chromosomal alterations. There are, however, indications that misrejoining of ends can also result from $\mathrm{Ku}$-dependent DSB repair, leading to exchange-type aberrations or insertions of DNA fragments. The parameters that influence the probability of misrejoining are not yet known; while physical closeness is a prerequisite for interaction between DNA ends, it is unclear whether, in DSB repair, ends from different break sites meet incidentally or whether active processes can bring them together. The ability of Ku to join ends originating from different break sites is not surprising, given that $\mathrm{Ku}$ is involved in $\mathrm{V}(\mathrm{D}) \mathrm{J}$ recombination and class switch recombination of immunoglobulin genes. However, at least for $\mathrm{V}(\mathrm{D}) \mathrm{J}$ recombination, the situation differs from DSB repair in that the regions to be joined are juxtaposed before cleavage occurs within a protein complex involving the RAG proteins [50].

Even when the correct ends are joined in the course of DSB repair, the Ku-mediated mechanism clearly introduces genetic alterations more readily than homologous recombination between sister chromatids. These alterations are, however, in general smaller than those introduced by $\mathrm{Ku}$-independent end joining. Thus, although $\mathrm{Ku}$-dependent 
DSB repair cannot be considered as an error-free mechanism, its general outcome appears to be less problematic than that of alternatives such as $\mathrm{Ku}$-independent end joining or ectopic homologous recombination. A clear positive effect of $\mathrm{Ku}$ results from its function in the telomeric cap: $\mathrm{Ku}$ suppresses chromosomal end-to-end fusions and, at least in yeast, recombination events in telomeric and telomereassociated regions. It will be interesting to see whether $\mathrm{Ku}$ has also an influence on the occurrence of ALT mechanisms in mammalian cells. Additional positive effects of $\mathrm{Ku}$ on genomic stability may include suppression of integrasemediated alterations. Thus, in spite of some negative effects, $\mathrm{Ku}$ can still be regarded as a caretaker of genomic stability.

\section{REFERENCES}

[1] Featherstone C, Jackson SP. Ku, a DNA repair protein with multiple cellular functions. Mutat Res. 1999;434(1):3-15.

[2] Kooistra R, Pastink A, Zonneveld JB, Lohmann PH, Eeken JC. The Drosophila melanogaster DmRAD54 gene plays a crucial role on double-strand break repair after P-element excision and acts synergistically with Ku70 in the repair of X-ray damage. Mol Cell Biol. 1999;19(9):6269-6275.

[3] Labhart P. Ku-dependent non-homologous DNA end joining in Xenopus egg extracts. Mol Cell Biol. 1999;19(4):2585-2593.

[4] Takata M, Sasaki MS, Sonoda E, et al. Homologous recombination and non-homologous end-joining pathways of DNA double-strand break repair have overlapping roles in the maintenance of chromosomal integrity in vertebrate cells. EMBO J. 1998;17(18):5497-5508.

[5] Grawunder U, Harfst E. How to make ends meet in $\mathrm{V}(\mathrm{D}) \mathrm{J}$ recombination. Curr Opin Immunol. 2001;13(2):186-194.

[6] Casellas R, Nussenzweig A, Wuerffel R, et al. Ku80 is required for immunoglobulin isotype switching. EMBO J. 1998;17(8):2404-2411.

[7] Manis JP, Gu Y, Lansford R, et al. Ku70 is required for late B cell development and immunoglobulin heavy chain class switching. J Exp Med. 1998;187(12):20812089.

[8] Bishop AJR, Schiestl RH. Homologous recombination and its role in carcinogenesis. J Biomed Biotechnol. 2002;2(2):76-86.

[9] Kadyk LC, Hartwell LH. Sister chromatids are preferred over homologs as substrates for recombinational repair in Saccharomyces cerevisiae. Genetics. 1992;132(2):387402.

[10] Johnson RD, Jasin M. Sister chromatid gene conversion is a prominent double-strand break repair pathway in mammalian cells. EMBO J. 2000;19(13):3398-3407.

[11] Lieber MR. The biochemistry and biological significance of nonhomologous DNA end joining: an essential repair process in multicellular eukaryotes. Genes Cells. 1999;4(2):77-85.
[12] Lewis LK, Resnick MA. Tying up loose ends: nonhomologous end-joining in Saccharomyces cerevisiae. Mutat Res. 2000;451(1-2):71-89.

[13] Boulton SJ, Jackson SP. Saccharomyces cerevisiae Ku70 potentiates illegitimate DNA double-strand break repair and serves as a barrier to error-prone DNA repair pathways. EMBO J. 1996;15(18):5093-5103.

[14] Milne GT, Jin S, Shannon KB, Weaver DT. Mutations in two $\mathrm{Ku}$ homologs define a DNA end-joining repair pathway in Saccharomyces cerevisiae. Mol Cell Biol. 1996;16(8):4189-4198.

[15] Liang F, Jasin M. Ku80-deficient cells exhibit excess degradation of extrachromosomal DNA. J Biol Chem. 1996;271(24):14405-14411.

[16] Kabyotanski EB, Gomelsky L, Han JO, Stamato TD, Roth DB. Double-strand break repair in Ku86- and XRCC4-deficient cells. Nucleic Acids Res. 1998;26(23): 5333-5342.

[17] Feldmann E, Schmiemann V, Goedecke W, Reichenberger S, Pfeiffer P, DNA double-strand break repair in cell-free extracts from Ku80-deficient cells: implications for $\mathrm{Ku}$ serving as an alignment factor in non-homologous end joining. Nucleic Acids Res. 2000;28(13):2585-2596.

[18] Manolis KG, Nimmo ER, Hartsuiker E, Carr AM, Jeggo PA, Allshire RC. Novel functional requirements for non-homologous DNA end joining in Schizosaccharomyces pombe. EMBO J. 2001;20(1-2):210-221.

[19] Liang F, Romanienko PJ, Weaver DT, Jeggo PA, Jasin M. Chromosomal double-strand break repair in Ku80-deficient cells. Proc Natl Acad Sci USA. 1996;93(17):8929-8933.

[20] Lee SE, Paques F, Sylvan J, Haber JE. Role of yeast SIR genes and mating type in directing DNA doublestrand breaks to homologous and non-homologous repair paths. Curr Biol. 1999;9(14):767-770.

[21] Chen S, Inamdar KV, Pfeiffer P, et al. Accurate in vitro end joining of a DNA double strand break with partially cohesive $3^{\prime}$-overhangs and $3^{\prime}$-phosphoglycolate termini: effect of $\mathrm{Ku}$ on repair fidelity. J Biol Chem. 2001;276(26):24323-24330.

[22] Kiechle M, Friedl AA, Manivasakam P, Eckardt-Schupp F, Schiestl RH. DNA integration by Ty integrase in yku70 mutant Saccharomyces cerevisiae. Mol Cell Biol. 2000;20(23):8836-8844.

[23] Stevens CW, Stamato TD, Mauldin SK, Getts RC, Zeng $\mathrm{M}$, Cerniglia GJ. Radiation-induced recombination is dependent on Ku80. Radiat Res. 1999;151(4):408-413.

[24] Yu X, Gabriel A. Patching broken chromosomes with extranuclear cellular DNA. Mol Cell. 1999;4(5):873881.

[25] Friedl AA, Kiechle M, Fellerhoff B, Eckardt-Schupp F. Radiation-induced chromosome aberrations in Saccharomyces cerevisiae: influence of DNA repair pathways. Genetics. 1998;148(3):975-988.

[26] Ferguson DO, Sekiguchi JM, Chang S, et al. The nonhomologous end-joining pathway of DNA repair is required for genomic stability and the suppression of 
translocations. Proc Natl Acad Sci USA. 2000;97(12): 6630-6633.

[27] Rothkamm K, Kühne M, Jeggo PA, Löbrich $M$. Radiation-induced genomic rearrangements formed by nonhomologous end-joining of DNA double-strand breaks. Cancer Res. 2001;61(10):3886-3893.

[28] McEachern MJ, Krauskopf A, Blackburn EH. Telomeres and their control. Annu Rev Genet. 2000;34:331-358.

[29] Dubrana K, Perrod S, Gasser SM. Turning telomeres off and on. Curr Opin Cell Biol. 2001;13(3):281-289.

[30] Blasco MA, Lee HW, Hande MP, et al. Telomere shortening and tumor formation by mouse cells lacking telomerase RNA. Cell. 1997;91(1):25-34.

[31] Dunham MA, Neumann AA, Fasching CL, Reddel RR. Telomere maintenance by recombination in human cells. Nat Genet. 2000;26(4):447-450.

[32] Niida H, Shinaki Y, Hande MP, et al. Telomere maintenance in telomerase-deficient mouse embryonic stem cells: characterization of an amplified telomeric DNA. Mol Cell Biol. 2000;20(11):4115-4127.

[33] Nakamura TM, Cooper JP, Cech TR. Two modes of survival of fission yeast without telomerase. Science. 1998;282:493-496.

[34] Gravel S, Larrivee M, Labrecque P, Wellinger RJ. Yeast $\mathrm{Ku}$ as a regulator of chromosomal DNA end structure. Science. 1998;280:741-744.

[35] Hsu HL, Gilley D, Blackburn EH, Chen DJ. Ku is associated with the telomere in mammals. Proc Natl Acad Sci USA. 1999;96(22):12454-12458.

[36] Bailey SM, Meyne J, Chen DJ, et al. DNA double-strand break repair proteins are required to cap the ends of mammalian chromosomes. Proc Natl Acad Sci USA. 1999;96(26):14899-14904.

[37] Hsu HL, Gilley D, Galande SA, et al. Ku acts in a unique way at the mammalian telomere to prevent end joining. Genes Dev. 2000;14(22):2807-2812.

[38] Samper E, Goytisolo FA, Slijepcevic P, van Buul PPW, Blasco MA. Mammalian Ku86 protein prevents telomeric fusions independently of the length of the TTAGGG repeats and the G-strand overhang. EMBO Rep. 2000;1(3):244-252.

[39] Fellerhoff B, Eckardt-Schupp F, Friedl AA. Subtelomeric repeat amplification is associated with growth at elevated temperature in yku70 mutants of Saccharomyces cerevisiae. Genetics. 2000;154(3):1039-1051.

[40] Baumann P, Cech TR. Protection of telomeres by the $\mathrm{Ku}$ protein in fission yeast. Mol Biol Cell. 2000;11(10):3265-3275.

[41] Polotnianka RM, Li J, Lustig AJ. The yeast Ku heterodimer is essential for protection of the telomere against nucleolytic and recombinational activities. Curr Biol. 1998;8(14):831-834.

[42] Daniel R, Katz RA, Skalka AM. A role for DNA-PK in retroviral DNA integration. Science. 1999;284:644-647.

[43] Coffin JM, Rosenberg N. Closing the joint. Nature. 1999;399:413-416.

[44] Baekelandt V, Claeys A, Cherepanov P, et al. DNA-dependent protein kinase is not required for efficient lentivirus integration. J Virol. 2000;74:1127811285.

[45] Li L, Olvera JM, Yoder KE, et al. Role of the nonhomologous DNA end-joining pathway in the early steps of retroviral infection. EMBO J. 2001;20:32723281.

[46] Caumont AB, Jamieson GA, Pichuantes S, Nguyen AT, Litvak S, Dupont CH. Expression of functional HIV-1 integrase in the yeast Saccharomyces cerevisiae leads to the emergence of a lethal phenotype: potential use for inhibitor screening. Curr Genet. 1996;29(6):503-510.

[47] Downs JA, Jackson SP. Involvement of DNA endbinding protein $\mathrm{Ku}$ in Ty element retrotransposition. Mol Cell Biol. 1999;19(9):6260-6268.

[48] Braiterman LT, Boeke JD. In vitro integration of retrotransposon Ty1: a direct physical assay. Mol Cell Biol. 1994;14(9):5719-5730.

[49] Roth DB, Gellert M. New guardians of the genome. $\mathrm{Na}$ ture. 2000;404:823-825.

[50] Hiom K, Gellert M. Assembly of a 12/23 paired signal complex: a critical control point in $\mathrm{V}(\mathrm{D}) \mathrm{J}$ recombination. Mol Cell. 1998;1(7):1011-1019.

* E-mail: anna.friedl@lrz. uni-muenchen.de Fax: +49895996 840; Tel: +49895996807 

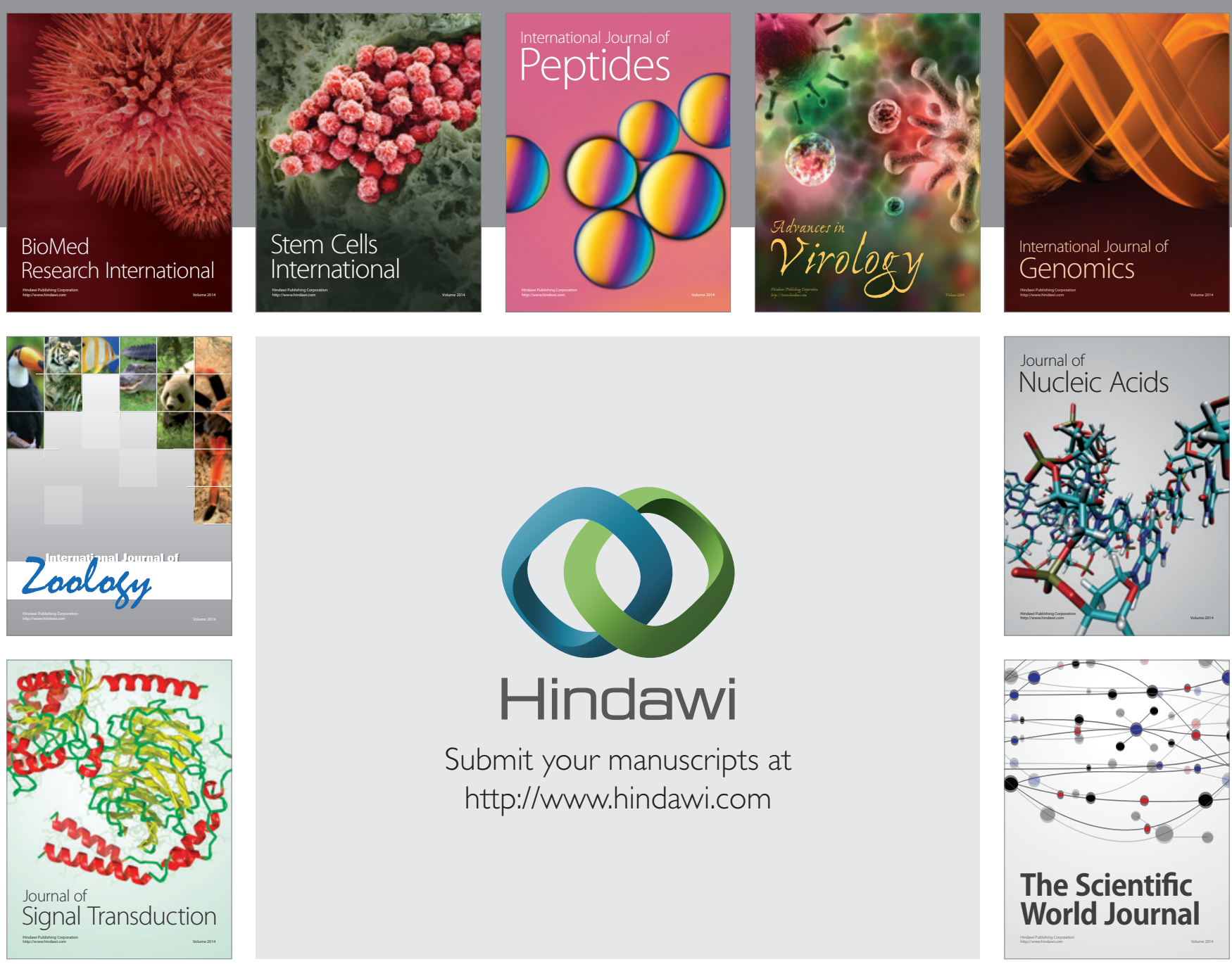

Submit your manuscripts at

http://www.hindawi.com
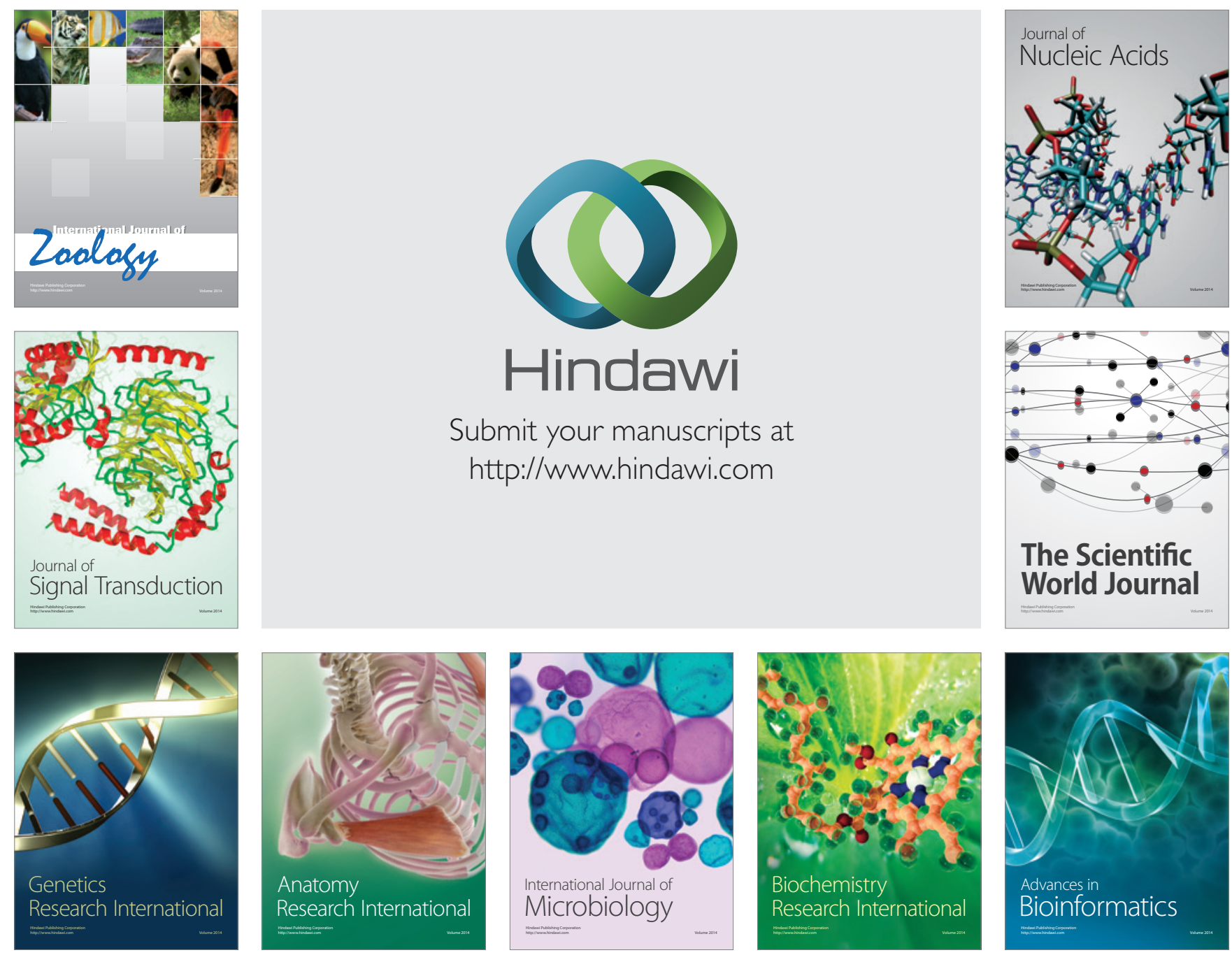

The Scientific World Journal
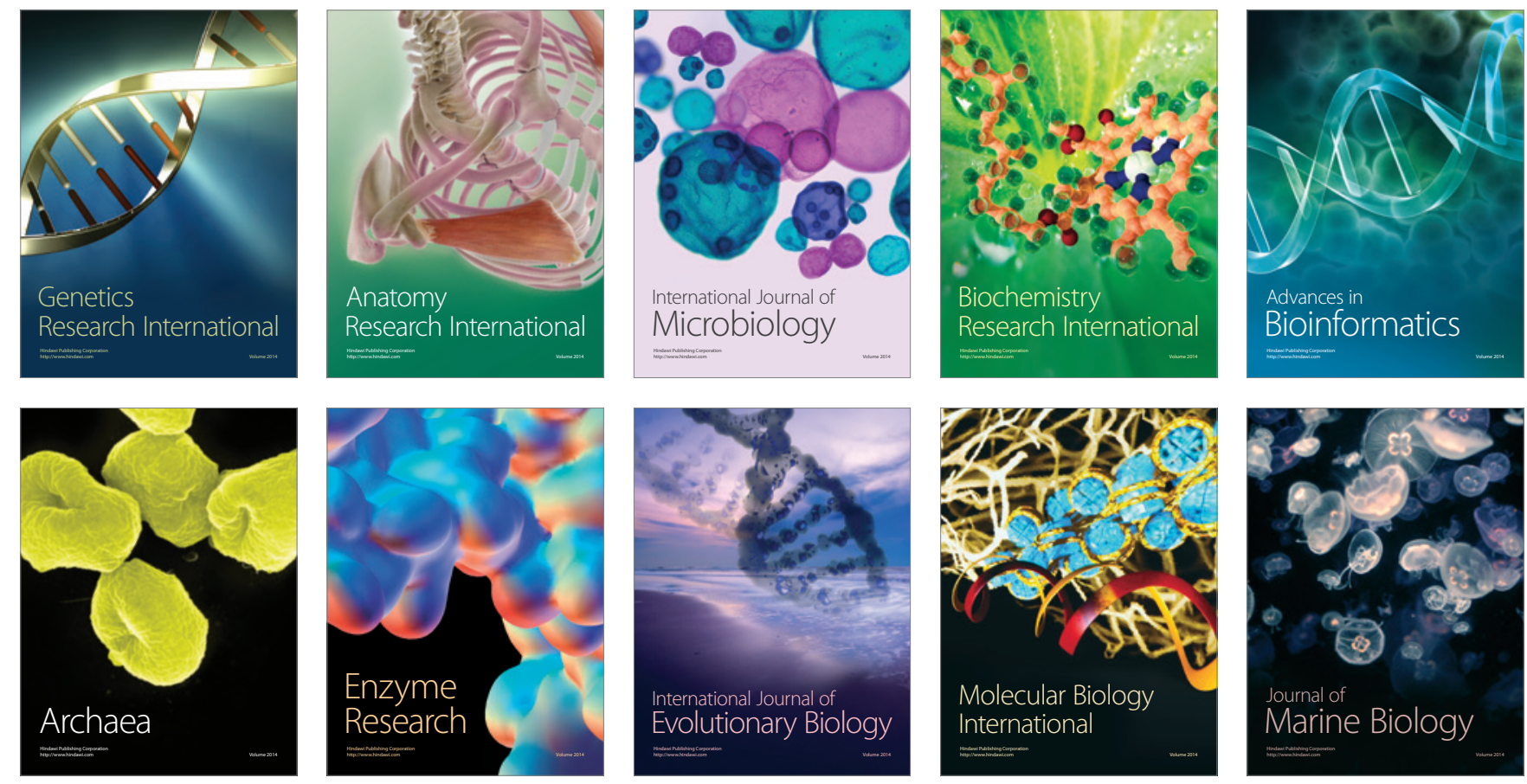